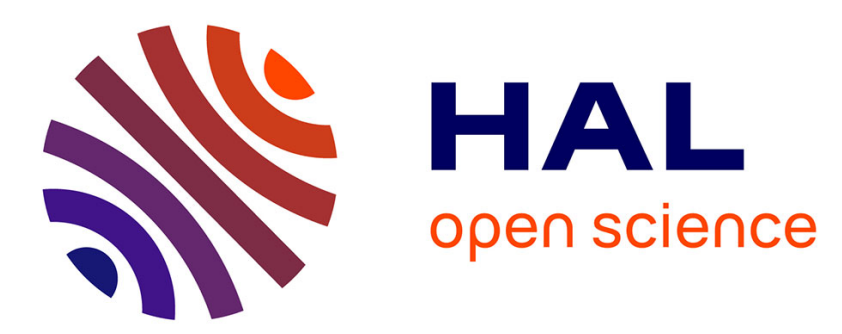

\title{
Efficient decoding of (binary) cyclic codes above the correction capacity of the code using Grobner bases
}

Daniel Augot, Magali Bardet, Jean-Charles Faugère

\section{To cite this version:}

Daniel Augot, Magali Bardet, Jean-Charles Faugère. Efficient decoding of (binary) cyclic codes above the correction capacity of the code using Grobner bases. IEEE International Symposium on Information Theory - ISIT'2003, Jun 2003, Yokohama, Japan. pp.362 - 362, 10.1109/ISIT.2003.1228378 . inria-00509269

\section{HAL Id: inria-00509269 \\ https://hal.inria.fr/inria-00509269}

Submitted on 11 Aug 2010

HAL is a multi-disciplinary open access archive for the deposit and dissemination of scientific research documents, whether they are published or not. The documents may come from teaching and research institutions in France or abroad, or from public or private research centers.
L'archive ouverte pluridisciplinaire HAL, est destinée au dépôt et à la diffusion de documents scientifiques de niveau recherche, publiés ou non, émanant des établissements d'enseignement et de recherche français ou étrangers, des laboratoires publics ou privés. 


\section{Efficient decoding of (binary) cyclic codes above the correction capacity of the code using Gröbner bases}

\author{
Daniel Augot \\ INRIA-Rocquencourt, Bat. 10 \\ Domaine de Voluceau, B.P. 105 \\ F-78153 Le Chesnay Cedex \\ e-mail: Daniel.Augot@inria.fr
}

\author{
Magali Bardet \\ Projet SPACES LIP6/LORIA \\ CNRS/UPMC/INRIA \\ 8, rue du capitaine Scott F-75015 Paris \\ e-mail: bardet@calfor.lip6.fr
}

\author{
Jean-Charles Faugère \\ Projet SPACES LIP6/LORIA \\ CNRS/UPMC/INRIA \\ 8, rue du capitaine Scott F-75015 Paris \\ e-mail: jcf@calfor.lip6.fr
}

\begin{abstract}
This paper revisits the topic of decoding cyclic codes with Gröbner bases. We introduce new algebraic systems, for which the Gröbner basis computation is easier. We show that formal decoding formulas are too huge to be useful, and that the most efficient technique seems to be to recompute a Gröbner basis for each word (online decoding). We use new Gröbner basis algorithms and "trace preprocessing" to gain in efficiency.
\end{abstract}

\section{INTRODUCTION}

Let $\mathcal{C}$ be a cyclic code of length $n$ over $\mathbb{F}_{2}$, with defining set $Q \subset\{1, \ldots, n\}$ and correction capacity $t$, and let $\alpha \in \mathbb{F}_{2^{m}}$ be a primitive $n$-th root of unity. For any error $e$ of weight $v$, if $Z_{j}^{*}$ denote the locators of $e$, we can compute its syndroms $S_{i}^{*}=e\left(\alpha^{i}\right)=\sum_{j=1}^{v} Z_{j}^{* i} \forall i \in Q$. As long as $v \leq t$, the system $\mathrm{SYN}_{v}=\left\{S_{i}-\sum_{j=1}^{v} Z_{j}^{i}, i \in Q\right\}$ specialized for $S_{i}=S_{i}^{*}$ has a unique solution (cf. [4]). To use the symmetry of the problem, we introduce the symmetric functions of the locators: $\mathrm{SYM}_{v}=\left\{\sigma_{j}-\sum_{l_{1}<\cdots<l_{j}} Z_{l_{1}} \cdots Z_{l_{j}}, j \in[1, v]\right\}$. The $S_{i}^{*}$ 's and the $\sigma_{j}^{*}$ 's associated to the $Z_{j}^{*}$ 's are also solutions of the following system (cf. [1])

$$
\operatorname{NEWTON}_{v}=\left\{\begin{array}{l}
S_{i}+\sum_{j=1}^{i-1} \sigma_{j} S_{i-j}+i \sigma_{i}, i \in[1, v] \\
S_{i}+\sum_{j=1}^{v} \sigma_{j} S_{i-j}, i \in[v, v+n-1]
\end{array}\right.
$$

A Gröbner basis describes the set $V_{\overline{\mathbf{K}}}(I)=\left\{x \in \overline{\mathbb{K}}^{s}: \forall f \in\right.$ $I, f(x)=0\}$ of solutions of an ideal $I \subset \mathbb{K}\left[x_{1}, \ldots, x_{s}\right]$ where $\overline{\mathbb{K}}$ is the algebraic closure of $\mathbb{K}$. To compute $V_{\mathbf{K}}(I)=V_{\overline{\mathbf{K}}}(I) \cap \mathbb{K}^{s}$, we have to add the field equations. We add $\mathbf{a}^{+}$to an ideal to denote the ideal together with the field equations $\left(Z_{j}^{n+1}\right.$ $Z_{j}, S_{i}^{2^{m}}-S_{i}$ or $\sigma_{j}^{2^{m}}-\sigma_{j}$ ).

It has been shown that the problem of decoding cyclic codes up to their true minimum distance can be solved by the use of Gröbner bases [3], with the algebraic system $\mathrm{SYN}_{v}^{+}$.

\section{NEW SYSTEMS AND THEIR PROPERTIES}

Starting from the system (1), we eliminate the unknowns syndroms $S_{i}, i \notin Q$ to obtain the new system BIN $=$ $\left\{S_{i}-f_{i}\left(\sigma_{1}, \ldots, \sigma_{v}\right) i \in Q\right\}$, where the $f_{i}$ 's are the Waring functions. We show that this new system and the systems $\mathrm{SYM}_{v}$ and NEWTON $v$ used in $[3,4]$ are closely related, and that for these systems the field equations are not necessary:

Proposition 1. The ideals and their variety are related by:

$$
\begin{aligned}
& \left\langle\mathrm{BIN}_{v}^{+}\right\rangle=\left\langle\mathrm{SYN}_{\mathrm{SYM}}^{+}\right\rangle \cap \mathbb{F}_{2}\left[\underline{\sigma}_{v}, \underline{S}\right]=\left\langle\mathrm{NEWTON}_{v}^{+}\right\rangle \cap \mathbb{F}_{2}\left[\underline{\sigma}_{v}, \underline{S}\right] \\
& \langle\mathrm{BIN}\rangle=\left\langle\operatorname{SYN}, \mathrm{SYM}_{v}\right\rangle \cap \mathbb{F}_{2}\left[\underline{\sigma}_{v}, \underline{S}\right]=\left\langle\mathrm{NEWTON}_{v}\right\rangle \cap \mathbb{F}_{2}\left[\underline{\sigma}_{v}, \underline{S}\right] \\
& V_{\overline{\mathbf{F}_{2}}}\left(\mathrm{SYN}_{\mathrm{SYM}}^{+}\right)=V_{\overline{\mathbf{F}_{2}}}\left(\mathrm{SYN}_{1}, \mathrm{SYM}_{v}\right) \\
& V_{\overline{\mathrm{F}}_{2}}\left(\text { NEWTON }_{v}^{+}\right)=V_{\overline{\mathrm{F}_{2}}}\left(\text { NEWTON }_{v}\right)
\end{aligned}
$$

\begin{tabular}{|c|c|c|c|c|}
\hline$n$ & $d$ & $\mathbb{F}_{2^{m}}$ & $v$ & number of multiplications in $\mathbb{F}_{2^{m}}$ \\
\hline 73 & 13 & $2^{9}$ & $3,4,5,6,7$ & $2^{5.4}, 2^{7.2}, 2^{10.5}, 2^{13.6}, 2^{17.4}$ \\
\hline 89 & 17 & $2^{11}$ & $3,4,5,6,7,8$ & $2^{5.1}, 2^{8.9}, 2^{11.6}, 2^{15.5}, 2^{20.3}, 2^{25.0}$ \\
\hline 113 & 15 & $2^{28}$ & $3,4,5,6,7,8$ & $2^{6.3}, 2^{8.9}, 2^{12.0}, 2^{15.6}, 2^{18.8}, 2^{23.9}$ \\
\hline
\end{tabular}

Table 1: Decoding QR Codes

Proposition 2 (Uniqueness). Let $\underline{S}^{*} \subset \mathbb{F}_{2^{m}}$ be the syndrom of an error $e$ of weight $v \leq t$, then the specialized system $\operatorname{Bin}\left(\underline{S}^{*}\right)$ has a unique solution $\left(\sigma_{1}^{*}, \ldots, \sigma_{v}^{*}\right)$ and $L_{e}(Z)=$ $\sum_{j=0}^{v} \sigma_{j}^{*} Z^{v}-j$ is the locator polynomial of e. In practice, the Gröbner basis of $\operatorname{BIN}\left(\underline{S}^{*}\right)$ is always $\left\{\sigma_{1}+\sigma_{1}^{*}, \ldots, \sigma_{v}+\sigma_{v}^{*}\right\}$.

Proposition 3 (List Decoding). If $v>t$ then the Gröbner basis of $\operatorname{BIN}\left(\underline{S}^{*}\right)$ gives all the possible errors of weight at most $v$ that have $\underline{S}^{*}$ as syndroms.

With these new systems, we are able to do formal decoding as well as online decoding. But the size of the formal formulas are so huge that the computation of the Gröbner basis is intractable, and even if we could obtain these formulas, the cost of their evaluation would be much too large.

\section{PRACTICAL DECODING}

In practice we do online decoding with a subset of the system BIN (we take the minimal number of equations to have a single solution, and choose the equations of minimal degree to speed the computation). This is a very general method, we only need the length and the defining set of the cyclic code.

If the field is big enough (e.g. $2^{20}$ ), we use a general method for solving systems with parameters: the behavior of the Gröbner basis computation is almost the same for all the possible values of the syndroms corresponding to an error of a given weight. Hence as a preprocessing, we can compute a Gröbner basis for $\operatorname{BIN}\left(S_{e_{0}}^{*}\right)$ for a random error $e_{0}$ of weight $v$, and record the trace of the computation (we do it as a $\mathrm{C}$ program). Then for any error $e$, the $C$ program executed on $\operatorname{BIN}\left(S_{e}^{*}\right)$ gives the values of the $\sigma_{j}$ 's. This reduce drastically the complexity of the online computation (by a factor 1000).

This method is implemented in Maple, and call the $\mathrm{C}$ software FGb from the third author to compute a Gröbner basis. $\mathrm{FGb}$ is an implementation of the algorithm F4 [2].

\section{REFERENCES}

[1] D. Augot. Description of minimum weight codewords of cyclic codes by algebraic systems. Finite Fields Appl, vol. 2, pp. 138-152, 1996.

[2] J.-C. Faugère. A new efficient algorithm for computing Gröbner bases $\left(F_{4}\right)$. J. Pure Appl. Algebra, 139(1-3):61-88, 1999.

[3] P. Loustaunau and E. Von York. On the decoding of cyclic codes using Gröbner bases. Appl. Algebra Eng. Commun. Comput., 8(6):469-483, 1997.

[4] I.S. Reed, T.K. Truong, X. Chen, and X. Yin. The algebraic decoding of the $(41,21,9)$ quadratic residue code. IEEE Trans. Inform. Theory, 38(3):974-986, 1992. 